\title{
Smoking during pregnancy in Finland - Trends in the MATEX cohort
}

\author{
ISABELL K. RUMRICH ${ }^{1,2}$, KIRSI VÄHÄKANGAS ${ }^{3}$, MATTI VILUKSELA $^{1,3}$, MIKA \\ GISSLER $^{4,5}$, HELJÄ-MARJA SURCEL ${ }^{6,7}$, ANTTI KORHONEN ${ }^{2}$, HANNA DE RUYTER $^{8}$ \& \\ OTTO HÄNNINEN²
}

\begin{abstract}
${ }^{1}$ University of Eastern Finland (UEF), Department of Environmental and Biological Sciences, Kuopio, Finland, ${ }^{2}$ National Institute for Health and Welfare (THL), Department of Public Health Solutions, Kuopio, Finland, ${ }^{3}$ University of Eastern Finland (UEF), School of Pharmacy/Toxicology, Kuopio, Finland, ${ }^{4}$ National Institute for Health and Welfare, Department of Information Services, Helsinki, Finland, ${ }^{5}$ Karolinska Institute, Department of Neurobiology, Care Sciences and Society, Division of Family Medicine, Huddinge, Sweden, ${ }^{6}$ University of Oulu, Faculty of Medicine, Finland, ${ }^{7}$ Biobank Borealis of Northern Finland, Oulu University Hospital, Finland, and ${ }^{8}$ Southern Ostrobothnia Central Hospital, Seinäjoki, Finland
\end{abstract}

\begin{abstract}
Aims: In Finland, smoking rates in the general population are decreasing due to increased awareness of the adverse effects and tightened tobacco legislation. However, previous studies have shown that smoking in pregnant Finnish women remained as high as in the general Finnish female population at around $15 \%$ in 2010 . Our aim was to describe temporal and spatial trends in smoking behaviour, and determinants of changes in smoking behaviour between first and second pregnancy. Methods: Self-reported smoking from the Finnish Medical Birth Register covered the years 1991-2015 (N=1,435,009). The association of maternal age and socioeconomic status with smoking rate was analysed. Spatial trends were assessed at municipality level. Results: The overall smoking rate during early pregnancy remained fairly stable at around $15 \%$ from 1991 to 2015 , but increased in teenage and young women below 25 years of age. The mean smoking rate (36\%) was higher in these age groups than in older pregnant women (11\%). Through the study period the smoking rate remained higher in blue collar workers compared with higher socioeconomic groups. Between the first and second child, on average only $4 \%$ of women started to smoke and $41 \%$ quitted. Smoking rates developed less favourably in Eastern Finland. Conclusions: The observed increase in smoking rate during pregnancy in teenage and young women is concerning. Pregnancy is a trigger point for smoking cessation in a big fraction of pregnant women. More studies are needed to explain the opposite trends of smoking rates in Northern and Western Finland compared with Eastern Finland.
\end{abstract}

Keywords: Tobacco, pregnancy, trends, maternal smoking, Finland, register study, intergenerational determinants, addiction

\section{Background}

Globally, smoking rate is decreasing since the general population is more aware of its adverse effects. Daily smoking in Finland remained slightly higher in men $(18 \%)$ than in women $(15 \%)$ in 2014 , despite a steady decrease in smoking rate in men since the 1970s. Among women, smoking increased until the mid-1980s and has decreased since then [1]. In 2010 smoking among pregnant Finnish women remained as high as in the general female population, and higher than among pregnant women in many other countries [2].

The sale and purchase of tobacco products are regulated by the Finnish Tobacco Act. The first Tobacco Act was passed in 1976 in an effort to reduce smoking among Finns. In 1994, the legal age limit was increased from 16 to 18 years,

Correspondence: Isabell K. Rumrich, University of Eastern Finland (UEF), Department of Environmental and Biological Sciences, National Institute for Health and Welfare (THL), Department of Public Health Solutions, P.O. Box 95, 70701 Kuopio, Finland. E-mail: Isabell.Rumrich@thl.fi

Date received 22 March 2018; reviewed 6 August 2018; accepted 8 September 2018

(C) Author(s) 2018

Article reuse guidelines: sagepub.com/journals-permissions

DOI: $10.1177 / 1403494818804417$

journals.sagepub.com/home/sjp 
advertisements and display in shops were banned, and smoking in public transport and government buildings was banned. In 2004 the ban was expanded to all public buildings and indoor workspaces and to pubs and restaurants in 2010 [3]. With the last reform of the Tobacco Act in 2010 Finland became the first country to pursue the eradication of tobacco products so that the smoking rate would be less than $2 \%$ in 2040 [4].

Children who are exposed in utero to smoking suffer from various neurobehavioural effects, and are more likely to smoke, have stronger nicotine dependence, and have higher risks for other substance abuse [5]. In a recent follow-up of the Finnish birth cohort maternal smoking during pregnancy increased the odds for daily smoking in offspring independently of other parental smoking behaviour [6]. The effect of maternal smoking on neurodevelopment is supported by the sensitivity of brain development to disturbances, and strong neurodevelopmental effects seen in animals treated prenatally with nicotine [7]. Similarly, smoking during pregnancy is associated with neurodevelopmental problems and increased risk for psychiatric morbidity later during childhood in humans [8].

Furthermore, smoking and nicotine exposure during pregnancy are associated with long-term effects in the child beyond neurodevelopment [9]. Other well-established effects of maternal smoking are low birth weight, preterm birth and small for gestational age [10]. These conditions and the effects of nicotine on lung development [11] increase the susceptibility for lung diseases in childhood, as well as diabetes and chronic cardiovascular diseases in adult life [12]. Furthermore, maternal smoking is associated with childhood obesity [13] and high childhood blood pressure [14]. Associations with congenital anomalies [15], stillbirths and sudden infant death syndrome [10] have also been reported.

It is essential to have an up-to-date understanding of smoking patterns and frequencies among pregnant women for planning of interventions and preventive measures in this important area of public health.

\section{Aims}

Our aim is to describe smoking behaviour and its determinants in pregnant women in Finland. Specifically, we (i) analyse temporal trends by age and socioeconomic status to identify risk groups; (ii) evaluate spatial differences in maternal smoking in Finland; and (iii) investigate determinants of changes in smoking behaviour in consecutive pregnancies.

\section{Methods}

Data sources

The MATEX birth cohort consists of a population based register of data identified from the Finnish Medical Birth Register (MBR), and it was used to investigate the smoking behaviour of pregnant women [16]. The baseline cohort consists of all births recorded in the MBR between 1 January 1987 and 31 December 2015, including 1.75 million children. The average annual number of births during that period was 57,400. The MBR receives information via standardized forms filled out by nurses and midwives during antenatal care visits and after the delivery. The MBR has been updated several times and the recording of the smoking behaviour changed from quantitative (number of cigarettes) in early pregnancy (1987-1990) to qualitative information (1991-2015). Our work focused on the qualitative data from 1991 to $2015(N=1,435,009)$. The cohort has been described in detail elsewhere [17].

In order to study the determinants of changes in smoking behaviour in consecutive pregnancies, we identified 368,390 women whose first and second pregnancies were recorded in the cohort.

\section{Variable definition}

Smoking behaviour was analysed based on four qualitative categories: (i) non-smoker, (ii) quitted smoking during the first trimester, (iii) continued smoking after the first trimester, and (iv) missing information. Categories (ii) and (iii) include all women who smoke during early pregnancy.

Socioeconomic status (SES) was defined based on maternal occupation recorded in the MBR. According to the Finnish national classification of occupations [18], SES was categorized as upper white collar (upper level employees with administrative, managerial, professional and related occupations), lower white collar (lower level employees with administrative and clerical occupations), blue collar (manual workers). Others (farmers, self-employed, students, pensioners, no information and information missing) were not included due to small group sizes and too much heterogeneity to aggregate.

Spatial trends were analysed on municipality level (municipality division as of 2016).

\section{Statistical analyses}

Smoking rate was calculated in reference to the total number of pregnant women. Temporal trends were studied from 1991 to 2015. Municipality level spatial trends were studied using five-year averages to 


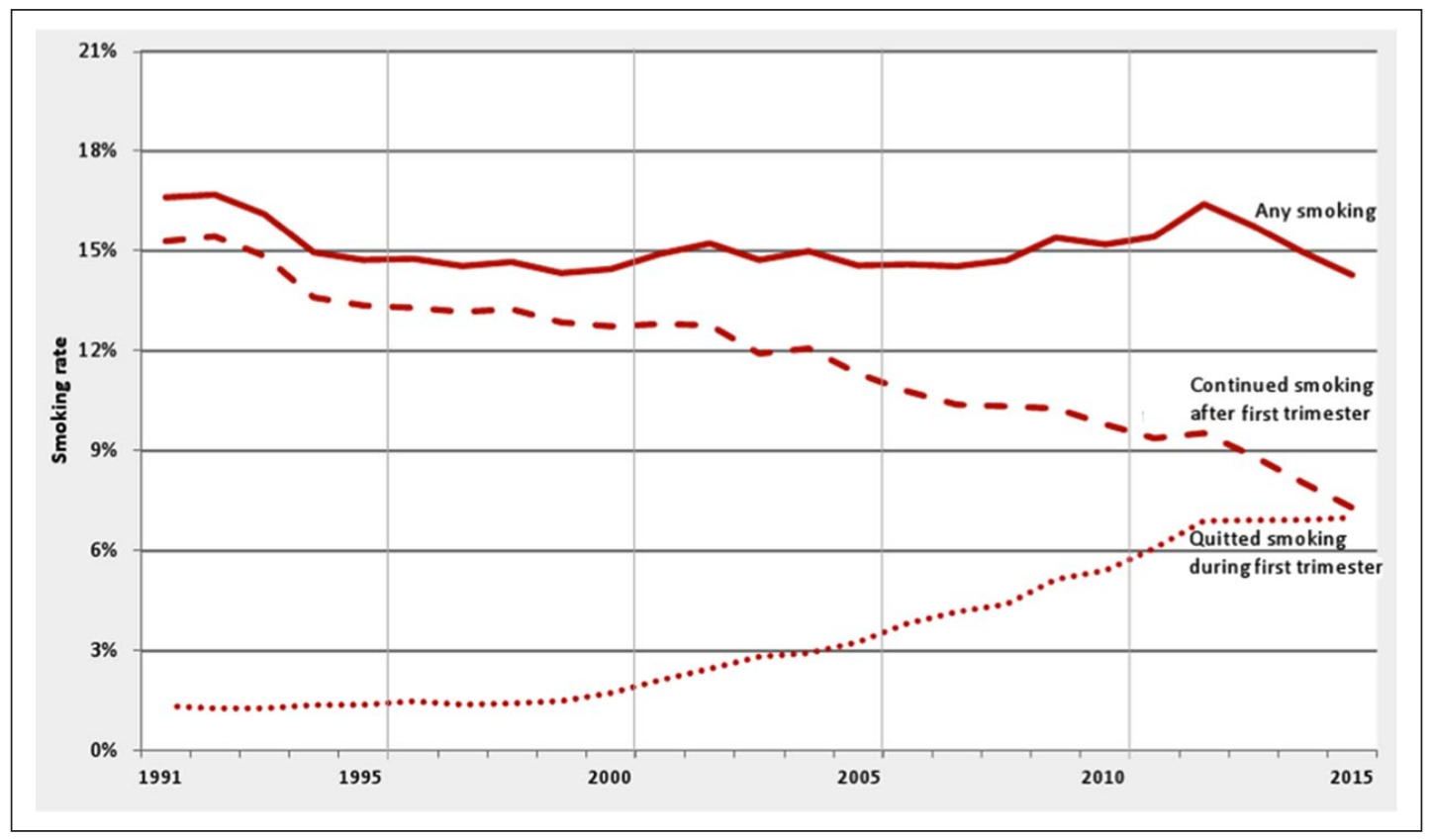

Figure 1. Smoking rates among pregnant women from 1991 to 2015.

decrease the random fluctuations in smoking rates in municipalities with low number of births. Differences in subgroups in comparison with the total population were calculated using chi-square test. All analyses were carried out in $\mathrm{R}$ Statistical Software version 3.4.3 and Microsoft Excel 2010.

\section{Ethics approval and right to use register data}

In accordance with the Finnish Medical Research Act (488/1999) the MATEX study including the birth cohort identified from the MBR has been approved by the ethics committee of the Northern Ostrobothnia Hospital District (EETTMK 44/2016; issued 18 April 2016). The right to use register data held by the National Institute for Health and Welfare was granted under document number THL/838/6.02.00/2016 (issued 22 June 2016). Due to the full register-based design of the study, no informed consent is required from the study participants according to the Finnish data protection legislation (Personal Data Act 523/1999).

\section{Results}

All smoking rates presented were calculated from the total of women giving birth in Finland.

\section{Smoking trends 1991-2015}

The MATEX cohort includes 1,435,009 mother-child pairs from 1991 to 2015 (smoking data available for $1,397,700$ women, $97.4 \%$ ). The overall smoking rate in Finnish women during early pregnancy fluctuated around the average of $15.1 \%$ (95\% confidence interval 14.5-15.8\%) between 1991 and 2015 (Figure 1). However, the fraction of women who quitted smoking during the first trimester increased steadily from $2 \%$ to $7 \%$ of all pregnant women, leading to a decrease in the fraction of women who continued smoking after the first trimester. Smoking was less prevalent in married women, women in a registered partnership and women who are cohabiting compared with unmarried, single women. Women who smoked in early pregnancy had a higher rate of previous miscarriages and previous abortions (Supplementary Material online, Table SI). Smoking in early pregnancy was more prevalent in women expecting their first child compared with women who were already mothers (Supplementary Figure S1). Smoking rates during early pregnancy were similar among the women expecting a singleton or multiples (15\% and $14 \%$, respectively).

Overall, smoking was more prevalent in pregnant blue collar workers than in pregnant white collar workers. The changes in smoking rates from 1991 to 2015 run parallel in the socioeconomic groups (Figure 2). An increase in the proportion of women who quitted smoking during the first trimester could be observed in all socioeconomic groups. Since 2008, the proportion of pregnant upper white collar women who quitted during the first trimester was higher than the proportion of pregnant upper white collar women who continued smoking after the first trimester. The same could be observed in lower white collar women since 2011. The highest smoking rate throughout the whole pregnancy was observed 


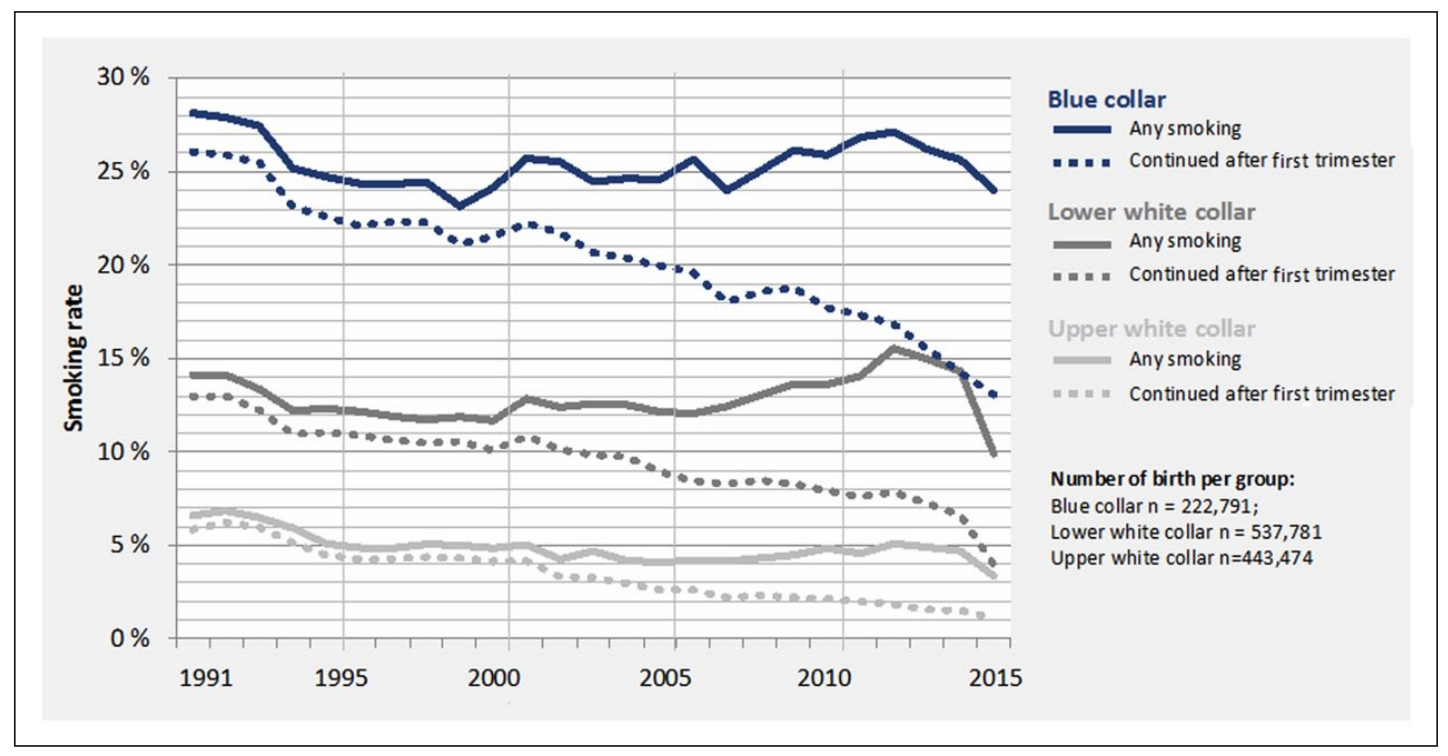

Figure 2. Temporal trends in smoking behaviour by socioeconomic groups. The solid lines show the smoking rates of any smoking during pregnancy and the dotted lines show the smoking rate after the first trimester.

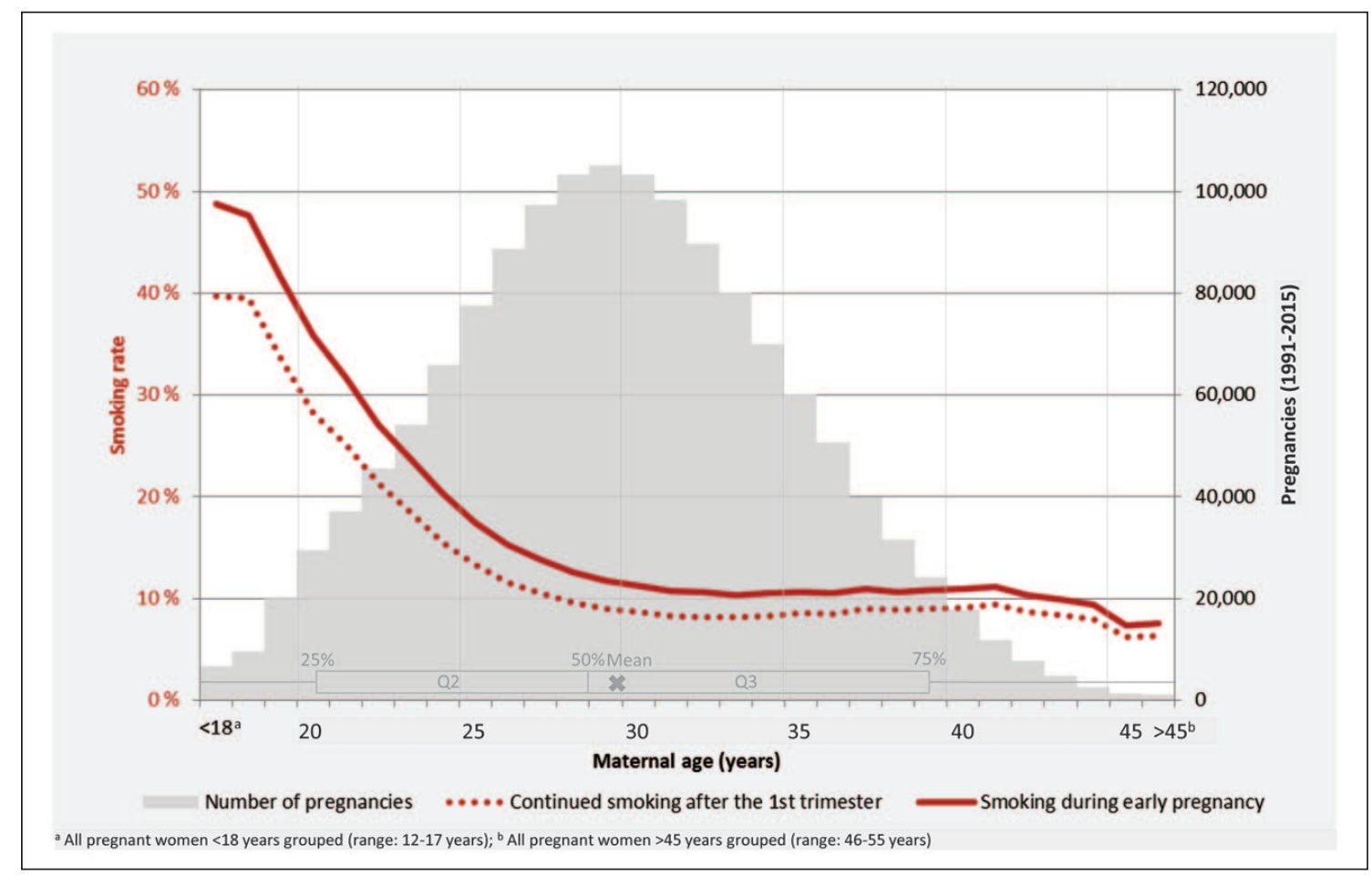

Figure 3. Age dependency of maternal smoking rates among Finnish pregnant women between 1991 and 2015.

among the blue collar workers. In 1991 the rate was $26 \%$ and it decreased to half by 2015 (Figure 2).

\section{Age dependency of smoking behaviour}

Maternal smoking rate was closely associated with the age of the pregnant women (Figure 3). Smoking rates during early pregnancy peaked during late teenage years and then flattened after the age of 30 years at around $10 \%$ of all pregnant women. The fraction of pregnant women quitting smoking during the first trimester was higher in young women than in older women. Temporal trends in smoking behaviour differed by age group (Supplementary Figure S2). The smoking rate in early pregnancy in teenagers and women in their $20 \mathrm{~s}$ increased statistically 
Table I. Changes in smoking status between first and second pregnancy of mothers having at least these two births in the data set $(n=368,390)$ stratified by socioeconomic status, maternal age and time between the pregnancies.

\begin{tabular}{|c|c|c|}
\hline $\begin{array}{l}\text { Change in smoking from first to second } \\
\text { pregnancy }\end{array}$ & Started & $\begin{array}{l}\text { Quitted before } \\
\text { second pregnancy }^{\mathrm{a}}\end{array}$ \\
\hline First pregnancy & $\begin{array}{l}\text { Non-smoking } \\
(n=303,130)\end{array}$ & $\begin{array}{l}\text { Any smoking } \\
(n=58,133)\end{array}$ \\
\hline Second pregnancy & $\begin{array}{l}\text { Any smoking } \\
(n=11,326)\end{array}$ & $\begin{array}{l}\text { Non-smoking } \\
(n=23,776)\end{array}$ \\
\hline Total $(n=386,390)$ & $3.7 \%$ & $40.9 \%$ \\
\hline \multicolumn{3}{|l|}{ Socioeconomic status at birth of the first child ${ }^{c}$} \\
\hline Upper white collar workers $(n=59,201)$ & $1.3 \%$ & $56.5 \%$ \\
\hline Lower white collar workers $(n=137,094)$ & $3.2 \%$ & $44.7 \%$ \\
\hline Blue collar workers $(n=56,413)$ & $6.5 \%$ & $36.9 \%$ \\
\hline \multicolumn{3}{|l|}{ Age at birth of the first child ${ }^{c}$} \\
\hline Teenagers $(n=23,364)$ & $15.5 \%$ & $29.4 \%$ \\
\hline $20-24$ years $(n=103,912)$ & $6.1 \%$ & $38.6 \%$ \\
\hline $25-29$ years $(n=150,862)$ & $2.5 \%$ & $47.5 \%$ \\
\hline$\geqslant 30$ years $(n=90,252)$ & $1.7 \%$ & $49.4 \%$ \\
\hline \multicolumn{3}{|l|}{ Calendar years between first and second child ${ }^{b}$} \\
\hline$<1$ year $(n=3044)$ & $5.3 \%$ & $32.4 \%$ \\
\hline 1 year $(n=119,156)$ & $2.5 \%$ & $42.5 \%$ \\
\hline 2 years $(n=117,745)$ & $2.7 \%$ & $43.9 \%$ \\
\hline $3-5$ years $(n=98,973)$ & $4.8 \%$ & $38.8 \%$ \\
\hline $6-10$ years $(n=25,606)$ & $10.0 \%$ & $37.2 \%$ \\
\hline $11-22$ years $(n=3866)$ & $15.2 \%$ & $37.6 \%$ \\
\hline
\end{tabular}

aFrom any smoking in the first pregnancy to no smoking in the second pregnancy.

${ }^{b}$ All displayed subgroups are statistically significantly $(p<0.001)$ different from the total pregnant population included in the analyses $(n=386,406)$.

significantly from 1991 to 2015 (42\% to $47 \%$ and $25 \%$ to $27 \%$, respectively; $p<0.001$ in both cases). The rate in women aged 30-44 years old decreased statistically significantly during the same period (from $13 \%$ to $10 \%, p<0.001$ ) The proportion of women who quitted smoking during the first trimester of pregnancy increased significantly among women younger than 45 years, from $1 \%$ to $7 \%$ $(p<0.001)$ (Supplementary Table SII).

\section{Smoking behaviour in consecutive pregnancies}

Nulliparous women $(n=368,390)$ were identified in the MATEX cohort and their smoking behaviour followed during the singleton pregnancies of their first and second child. Changes were analysed in two main groups: (i) fraction of women smoking during the second pregnancy among women who did not smoke during their first pregnancy, (ii) fraction of women not smoking during the second pregnancy among women smoking during the first pregnancy

More than three-quarters $(77.2 \%)$ of women did not smoke during either pregnancy. Only $3.7 \%$ of women who were non-smokers in their first pregnancy smoked during their second pregnancy. The fraction of women starting to smoke was higher among blue collar than white collar workers, among younger than older women and among those with a very short or very long time between the consecutive children (Table I). Overall, $40.9 \%$ of all women who smoked during the first pregnancy ceased smoking before their second child. Upper white collar workers, young (25-29 years) women, those with 3-5 years between pregnancies and women who gave birth later ( $\geqslant 30$ years) were more likely to stop smoking from their first to their second child. The highest percentage $(9 \%)$ of smoking initiation between the first and second child was observed among blue collar women (Table I). Few women $(6.3 \%)$ who smoked throughout their first pregnancy quitted smoking during their second pregnancy (Supplementary Table SIII).

\section{Spatial trends}

Spatial analyses of smoking during early pregnancy rates were based on the five-year average at municipality level. A general trend in increasing smoking rates in Southern Finland, and especially in Eastern Finland, was evident and a reduction of smoking in Lapland (northernmost Finland) could be observed (Figure 4; Supplementary Figure S3). Throughout this period a lower smoking rate prevailed in Western Finland compared with Eastern Finland. Smoking rates were lower in municipalities in Western Finland 


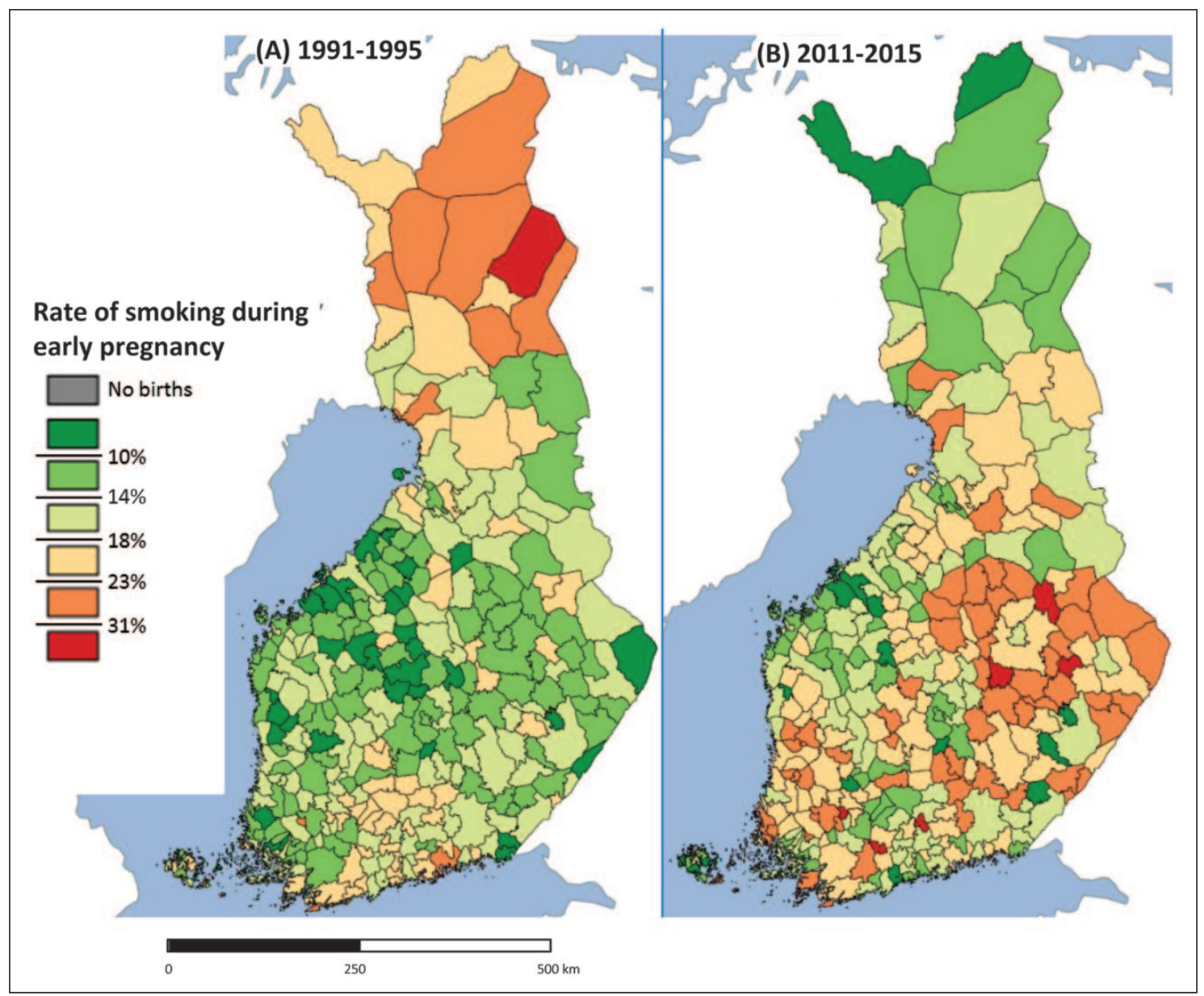

Figure 4. Smoking rates during early pregnancy in Finland by five-year average for 1991-1995 and 2010-2015.

compared with the national average, whereas the smoking rates in Southern and Eastern municipalities were higher than the national average (Supplementary Figure S4).

\section{Discussion}

The smoking rates during early pregnancy remained fairly stable, at around 15\% between 1991 and 2015 . At the same time, the fraction of women who ceased smoking during the first trimester steadily increased. A higher fraction of blue collar workers smoked compared with upper and lower white collar workers. Overall, little change in previously identified risk groups has been observed. On average, smoking was less prevalent in Western Finland than in Eastern Finland between 1991 and 2015.

\section{Temporal trends}

In contrast to the development in other Nordic countries [19], this study found no stable long-term decrease in smoking rates during early pregnancy in
Finland between 1991 and 2015, but there was indication for a decrease since 2008. Marked differences between the temporal development in the general female population and in pregnant women have been reported. Smoking within the general female population has been more common in Norway and Denmark than in Finland [20]. The stagnation in observed smoking rates among pregnant women in Finland is driven by decreasing smoking rates among older women and an increase among teenagers and young women. A positive development is the increasing rate among those who quit smoking during the first trimester and a decreasing trend among those who continue to smoke throughout the pregnancy.

The observed increase in the fraction of smoking pregnant teenagers and young women may be explained by a change in the pregnant population. It is possible that smoking is an indicator of a more vulnerable population among which more young women get pregnant, due to, for example, earlier sexual contacts and risky behaviour as well as poorer health education and health literacy [21]. This theory is supported by a decreasing smoking rate within the 
general female population aged 15 to 24 years in Finland from around $23 \%$ in 1994 to around 15\% in 2014. Furthermore, daily smoking among Finnish female teenagers (14-18 years) has decreased dramatically since 2000 , from $25 \%$ to $7 \%$ [22].

\section{Spatial trends}

Spatial differences in the development of maternal smoking rates became evident. While the development in Lapland during early pregnancy is positive, there was a constant increase in Eastern Finland up to 2015. The same general development can be seen in the general health of the Finnish population, as indicated by THL's morbidity index [23]. The sales of alcoholic beverages per capita, measured as litres of pure alcohol, are also higher in Eastern Finland [24], which may indicate a less health conscious lifestyle and potentially poorer health literacy.

The observed differences between individual municipalities may be explained by sociographic differences in the municipalities, such as distribution of socioeconomics and education. Additionally, health education in schools and prioritization of smoking cessation consultations in antenatal care settings probably differ between municipalities. A different fraction of risk groups within municipalities may partly explain the observed differences. This idea is supported by studies showing that smoking is determined not only by individual SES, but also by the wider environment. The smoking rate among pregnant women was shown to be more common in most deprived municipalities during 2005-2010, regardless of the SES of the pregnant women [25].

\section{Risk groups and legislation}

The steep decrease in the percentage of the blue collar women who smoked after the first trimester of pregnancy was a positive trend. However, the increase in the smoking rate in early pregnancy among young girls and women is of concern. As explained above, the very young pregnant girls and women are a high risk subgroup of the general population which is engaging in overall risky health behaviour. Studies have revealed several risk factors associated with teenage pregnancy, such as disadvantaged socioeconomic background, disrupted family structure and low educational level. These shared risk factors for smoking and teenage pregnancy demonstrate the challenges in smoking interventions among pregnant teenagers.

The aim in Finland is to reduce smoking to below $2 \%$ by 2040 [4], among other things by preventing adolescents starting to smoke [26]. Higher smoking rates among the teenagers attending vocational school compared with their peers in high school [22] may reflect potential differences in health education between the different types of schools. The higher smoking rate in nulliparous women compared with multiparous women may be explained by the on average older age of multiparous women compared with nulliparous women.

\section{Pregnancy as a time of opportunity}

Possible changes in smoking behaviour of women while being pregnant with their first and second child are associated with SES, maternal age, the time between the pregnancies and the birth year. Overall, about $4 \%$ of women started to smoke between the first and the second child, while $41 \%$ gave up smoking during the same period. However, only two-thirds of women who quitted smoking during the first trimester of their first pregnancy remained smoke-free in their second pregnancy. This emphasizes the importance of intervention before and during pregnancy to cease smoking. Pregnancy is an opportunity to motivate women to cease smoking and to remain smoke-free, and the focus of intervention and more support should be targeted on pregnant women.

Population-based intervention in Finland was shown to be an efficient tool to encourage pregnant women to stop smoking [27]. This shows that pregnancy is a sensitive moment and if smoking cessation was made a priority in antenatal care settings, the fraction of women who cease smoking might increase significantly. This, however, only solves part of the problem, and it would be much more efficient to prevent the onset of smoking in young girls.

\section{Strengths and limitations of the study}

Self-reported smoking recorded in the MBR is lower than what can be judged by serum cotinine [3]. Cotinine analyses of randomly selected serum samples of pregnant women showed a non-disclosure rate of $8 \%$ (self-reported non-smoking, but detectable cotinine concentrations) while $5 \%$ of self-reported smokers had cotinine concentrations below the detection level. No temporal changes in the rate of smokers with a low cotinine level or women who non-disclosed smoking was observed [3].

A limitation of this study is the coarse qualitative nature of the exposure categories. We lack information whether the women smoked daily or how many cigarettes. Also, we do not have information of the exact time of smoking cessation at any point after the first trimester or if the women reduced smoking. Thus, trends in reduction of smoking beyond cessation cannot be analysed with our data. Many adverse 
effects of smoking follow a clear dose-response relationship, so the reduction of smoking already has clear benefits. Several blood samples taken throughout the pregnancy and analysed for nicotine exposure would be beneficial to evaluate temporal patterns of smoking.

\section{Conclusions}

Despite the anti-smoking policies, the smoking rate of women during early pregnancy in Finland remained at about $15 \%$ throughout 1991 to 2015 . However, the fraction of women who ceased smoking during the first trimester increased steadily during the study period. Maternal smoking was shown to be associated with sociodemographic factors. It was more common at young age and among blue collar workers than among older pregnant women and white collar workers. Throughout the study period, a lower smoking rate was observed in Western than in Eastern Finland. Pregnancy has been shown to be a time of opportunity for smoking cessation with $40 \%$ of women ceasing smoking from their first to their second pregnancy. More effort is needed to prevent the initiation of smoking among young girls and women to reduce the smoking rates long term. More studies are needed to evaluate the differences between municipalities with favourable development since 1991 and those municipalities where smoking rates increased. Currently, the Finnish MBR contains smoking status self-reported by pregnant women during antenatal care visits. However, inclusion of information on exposure to second-hand smoke and other nicotine sources (nicotine replacement therapy, e-cigarettes) is needed for more advanced epidemiological research on the effects of prenatal exposures.

\section{Acknowledgements}

With gratitude we acknowledge the support for the implementation of MATEX cohort and registerbased research infrastructure at the Department of Public Health Solutions and the ROKOSTAT-team, especially Esa Ruokokoski and Jonas Sundman for setting up the Linux Cluster environment and implementing the Medical Birth Register linkage. We also thank for the essential support from the Register Holder by Jouni Meriläinen.

\section{Declaration of conflicting interests}

$\mathrm{KV}$ is currently the chair of the scientific committee of the Savuton Suomi (Smoke-free Finland) 2030 initiative. Other authors declare that they do not have a conflict of interest.

\section{Funding}

This work was supported by the Juho Vainio Foundation (grant numbers 201510322, 201610405, 201710136); NordForsk under the Nordic Programme on Health and Welfare project NordicWelfAir (grant number 75007); Academy of Finland project BATMAN (grant number 285672), the EU Life project Index Air (grant number LIFE15ENV/PT/000674), Finnish Cultural Foundation North Savo Regional Fund (grant number 65161550) to IKR, and intramural funding by the participating institutes and intramural funding of the institutions.

\section{References}

[1] Helldán A and Helakorpi S. Suomalaisen aikuisväestön terveyskäyttäytyminen ja terveys, kevät 2014. [Health behaviour and health among the Finnish Adult Population, Spring 2014], http://www.julkari.fi/bitstream/handle /10024/126023/URN_ISBN_978-952-302-447-2. pdf?sequence $=1$ \&isAllowed $=y$ (accessed 3 October 2018).

[2] Reitan T and Callinan S. Changes in smoking rates among pregnant women and the general female population in Australia, Finland, Norway, and Sweden. Nicotine Tob Res 2017; 19: 282-289.

[3] Männistö T, Bloigu A, Heino A, et al. Changes in objectively measured smoking in pregnancy by time and legislative changes in Finland: A retrospective cohort study. BMF Open 2016; 6: e013296.

[4] Ministry of Social Affairs and Health. Roadmap to a tobaccofree Finland. Action Plan on Tobacco Control, http:// julkaisut.valtioneuvosto.fi/bitstream/handle/10024/70305/ URN_ISBN_978-952-00-3513-6.pdf (2014, accessed 3 October 2018).

[5] Pauly JR and Slotkin TA. Maternal tobacco smoking, nicotine replacement and neurobehavioural development. Acta Pcediatr 2008; 97: 1331-1337.

[6] Niemela S, Raisanen A, Koskela J, et al. The effect of prenatal smoking exposure on daily smoking among teenage offspring. Addiction 2017; 112: 134-143.

[7] Hellstrom-Lindahl E and Nordberg A. Smoking during pregnancy: A way to transfer the addiction to the next generation? Respiration 2002; 69: 289-293.

[8] Ekblad M, Lehtonen L, Korkeila J, et al. Maternal smoking during pregnancy and the risk of psychiatric morbidity in singleton sibling pairs. Nicotine Tob Res 2017; 19: 597-604.

[9] England LJ, Aagaard K, Bloch M, et al. Developmental toxicity of nicotine: A transdisciplinary synthesis and implications for emerging tobacco products. Neurosci Biobehav Rev 2017; 72:176-189.

[10] Cnattingius S. The epidemiology of smoking during pregnancy: Smoking prevalence, maternal characteristics, and pregnancy outcomes. Nicotine Tob Res 2004; 6: 125.

[11] McEvoy CT. and Spindel ER. Pulmonary effects of maternal smoking on the fetus and child: Effects on lung development, respiratory morbidities, and life long lung health. Paediatr Respir Rev 2017; 21:27-33.

[12] Kramer MS, Seguin L, Lydon J, et al. Socio-economic disparities in pregnancy outcome: Why do the poor fare so poorly? Paediatr Perinat Epidemiol 2000; 14: 194-210.

[13] Ino T. Maternal smoking during pregnancy and offspring obesity: Meta-analysis. Pediatr Int 2010; 52: 94-99.

[14] Brion MJ, Leary SD, Lawlor DA, et al. Modifiable maternal exposures and offspring blood pressure: A review of 
epidemiological studies of maternal age, diet, and smoking. Pediatr Res 2008; 63: 593-598.

[15] Hackshaw A, Rodeck C and Boniface S. Maternal smoking in pregnancy and birth defects: A systematic review based on 173687 malformed cases and 11.7 million controls. Hum Reprod Update 2011; 17: 589-604.

[16] National Institute for Health and Welfare. Medical Birth Register, https://www.thl.fi/fi/web/thlfi-en/statistics /information-on-statistics/register-descriptions/newborns (2016, accessed 11 December 2017).

[17] Rumrich IK, Vahakangas K, Viluksela $M$, et al. The MATEX cohort - a Finnish population register birth cohort to study health effects of prenatal exposures. BMC Public Health 2017; 17: 8 .

[18] Statistics Finland. Finnish national classification of occupations, https://www.stat.fi/meta/luokitukset/ammatti/001 -2010/index_en.html (2010, accessed 3 October 2018).

[19] Ekblad M, Gissler M, Korkeila J, et al. Trends and risk groups for smoking during pregnancy in Finland and other Nordic countries. Eur F Public Health 2013; 24: 544-551.

[20] Ásgeirsdóttir TL and Gerdtham U. Health behavior in the Nordic countries. Nord 7 Health Econ 2016; 4: 28-40.

[21] Lantz PM. Smoking on the rise among young adults: Implications for research and policy. Tob Control 2003; 12: 60 .

[22] Kinnunen J, Pere L, Raisamo S, et al. Nuorten terveystapatutkimus 2017: Nuorten tupakkatuotteiden ja päihteiden käyttö sekä rahapelaaminen [The Adolescent Health and Lifestyle Survey 2017: Adolescent smoking, alcohol use and gambling], http://julkaisut.valtioneuvosto.fi /bitstream/handle/10024/80160/V2_kirjanmerkit_20170824 Suomi\%20100_NTTT2017_korjaukset_mukana\%20
$\% 282 \% 29$.pdf? sequence $=1$ \&isAllowed $=y \quad$ (accessed 3 October 2018).

[23] Statistical information on welfare and health in Finland. THL's morbidity index, age-standardised, https://www.sot kanet.fi/sotkanet/en/kartta?indicator=szYOAAA $=$ \&region =VVBJCgNBCPxRg0szDL4j11w8BHLN_2-jlpMYGt SuKlfjxU7KxoucxV7p7AirJhUX0fH5RcT2T0Niuih wTu9KrSS1TZyvcIELeYF309mB9K8fj6qcoYAu1AX 4qKIgRlKXhdfCBaMctQUspLFRkJGeC6VyjvdOu3suwb F0nAMWdB_DBSPL_YXorP1NP_6sIz4u\&year=sy4rBQ $\mathrm{A}=\&$ gender $=\mathrm{t}$ (2014, accessed 16 January 2018).

[24] Statistical information on welfare and health in Finland. Sale of alcoholic beverages per capita, as litres of pure alcohol, https:// www.sotkanet.fi/sotkanet/en/kartta?indicator $=\mathrm{s} 05 \mathrm{KBAA}=\&$ region=VVBJCgNBCPxRg0szDL4j11w8BHLN_2-jlpMYGt SuKlfjxU7KxoucxV7p7AirJhUX0fH5RcT2T0Niuih wTu9KrSSITZyvcIELeYF309mB9K8fj6qcoYAu1AX4qKI gRlKXhdfCBaMctQUspLFRkJGeC6VyjvdOu3suwbF OnAMWdB_DBSPL_YXorP1NP_6sIz4u\&year=sy4rAwA=\& gender=t, (2014, accessed 16 January 2018).

[25] Raisanen S, Kramer MR, Gissler M, et al. Smoking during pregnancy was up to $70 \%$ more common in the most deprived municipalities - a multilevel analysis of all singleton births during 2005-2010 in Finland. Prev Med 2014; 67: $6-11$.

[26] Savuton Suomi. Tobacco-free Finland 2030 (savuton suomi), http://savutonsuomi.fi/en/ (2012, accessed 27 November 2017).

[27] Jaakkola N, Zahlsen K and Jaakkola JJ. Effects of a population-based smoking cessation programme on smoking in pregnancy. Eur f Public Health 2001; 11: 446-449. 